\title{
Original
}

\section{Non-touch, Quick Destruction of the Tracheal Occluding Balloon Using HIFU}

\author{
Shunsuke Osawa ${ }^{1)}$, Tomoo SATO ${ }^{2)}$, Hiromasa YAmashita ${ }^{3)}$, \\ Takashi MochizUKI ${ }^{4)}$, Gontaro KitAZUMI ${ }^{5)}$, Jacques JANI ${ }^{6}$, \\ Akira TokI $^{1)}$ and Toshio CHIBA ${ }^{* 3)}$
}

\begin{abstract}
The technique of fetal endoscopic tracheal occlusion (FETO) was developed to totally occlude the fetal trachea using an intratracheal balloon in the treatment of congenital diaphragmatic hernia with lung hypoplasia. To improve this approach, we developed a method for non-contact, rapid destruction of the balloon using high intensity focused ultrasound (HIFU), a specific balloon injection fluid, and euthanized rabbits $(1 \mathrm{~kg})$. In an initial experiment (5 rabbits), we inflated an intratracheal balloon by injecting in $1.0 \mathrm{ml}$ of fluid and demonstrated that HIFU could successfully burst the balloon in all cases, although the tracheal membranous portion and the skin overlying the trachea were injured in 4 and 2 cases, respectively. In our second experiment ( 6 animals), we inflated the balloon using only $0.5-0.6 \mathrm{ml}$ of fluid. In all cases, HIFU either burst ( 1 animal) or deflated ( 5 animals) the balloon and there was substantially decreased injury of the tracheal membranous portion ( 2 cases) or overlying skin ( 2 cases). The total HIFU energy output revealed no significant difference between the first and second experimental groups. In conclusion, the intratracheal balloon placed by FETO can be removed using HIFU alone.
\end{abstract}

Key words : High Intensity Focused Ultrasound (HIFU), Fetal Endoscopic Tracheal Occlusion (FETO), Congenital Diaphragmatic Hernia (CDH)

\section{Introduction}

Congenital diaphragmatic hernia $(\mathrm{CDH})$ is occasionally associated with severe lung hypoplasia, which can potentially cause prenatal or postnatal death ${ }^{1,2)}$. Fetal endoscopic tracheal occlusion (FETO) is a minimally invasive prenatal procedure used to promote fetal lung growth by occluding the fetal trachea using a balloon fetoscopically inflated inside the trachea ${ }^{3,4)}$. Although FETO has been widely adopted with increased success, safe removal of the tracheal occlusion before delivery remains a crucial issue ${ }^{4,5)}$. Several procedures have been reported for removing

\footnotetext{
1) Department of Surgery, Division of Pediatric Surgery, Showa University School of Medicine, 1-5-8 Hatanodai, Shinagawa-ku, Tokyo 142-8666, Japan.

2) Port and Airport Research Institute.

3) University Research Center, Nihon University.

4) Medical Ultrasound Laborator.

5) Control AD Corp.

6) Department of Gynecology and Obstetrics, Brugmann University Hospital.

* To whom corresponding should be addressed.
} 
the intratracheal balloon following a FETO procedure including removal of the balloon in a second fetoscopic procedure. However, any prenatal procedure invariably requires a high degree of technical competence and expertise, and this might be problematic in emergency cases involving an unexpected preterm delivery. To overcome this problem, we have developed a relatively safe and simple solution that combines two procedural concepts: a specifically designed irradiation sequence of high intensity focused ultrasound (HIFU) and a specifically formulated fluid for balloon inflation. Using animal models, we were able to instantaneously destroy or progressively deflate an intratracheal balloon and open the occluded trachea. In this paper, we report on our research and experimental results and discuss the likelihood of prospectively avoiding a second fetoscopy following the conventional FETO procedure.

\section{Materials and methods}

Rabbits (Japanese white, male, $1 \mathrm{~kg}$ ) were used in this study to model a human fetus floating in the uterine cavity filled with amniotic fluid. Five rabbits were used in experiment 1 and six rabbits in experiment 2. The animals were euthanized then submerged in a water tank filled with degassed water. A fetoscope (Karl Storz, Tuttlingen, Germany; Model 11540AA, Miniature Straight Forward Telescope $0^{\circ}, 1.3 \mathrm{~mm}$ ) was inserted into the trachea of each rabbit, while injecting water so as not to damage the vocal cords. A balloon (BALT Extrusion, Montmorency, France; GOLDBAL2, $7.0 \times 22 \mathrm{~mm}$ when fully expanded, designated injection volume $0.6 \mathrm{ml}$ ) was placed in the middle of the trachea and inflated by injecting a specific fluid under ultrasound guidance. The injection fluid was a perfluorocarbon mix of Phase-Change Nanodroplet [HITACHI, Tokyo, Japan ;6,7)] and Sonazoid ${ }^{\mathbb{R}}$ [Daiichi-Sankyo Pharmaceuticals, Tokyo Japan ; ${ }^{8,9)}$. Both fluid components were biologically safe ${ }^{10)}$ and served to aid the sonographic identification and then HIFU destruction of the intratracheal balloon.

\section{Experiment 1}

The HIFU irradiation was focused onto the back wall of the balloon, which was inflated with $1.0 \mathrm{ml}$ of the injection fluid (Fig. 1). Prior to this experiment, we tested the balloon valve function at $37^{\circ} \mathrm{C}$ by injecting $1.0 \mathrm{ml}$ fluid and found no valve leakage over at least 7 days. The HIFU transducer was driven at $1.0 \mathrm{MHz}$ with an aperture diameter of $120 \mathrm{~mm}$ and a focal depth of $120 \mathrm{~mm}$. The acoustic intensity of HIFU was $3 \mathrm{~kW} / \mathrm{cm}^{2}$ and the maximum exposure time was $30 \mathrm{~s}$. The HIFU exposure sequence comprised an initial series of high intensity trigger pulses $(20 \mu \mathrm{s})$ seamlessly followed by moderate intensity heating waves $(400 \mathrm{~ms})$. If the balloon was not destroyed after the first cycle of HIFU exposure, the irradiation was repeated under the same conditions for up to three cycles. HIFU irradiation was discontinued when the balloon was destroyed by deflation or bursting.

\section{Experiment 2}

As in experiment 1, the balloon was placed inside the trachea and was inflated with $0.5-0.6 \mathrm{ml}$ of the injection fluid. HIFU was applied as described in experiment 1 (i.e., trigger pulses coupled 


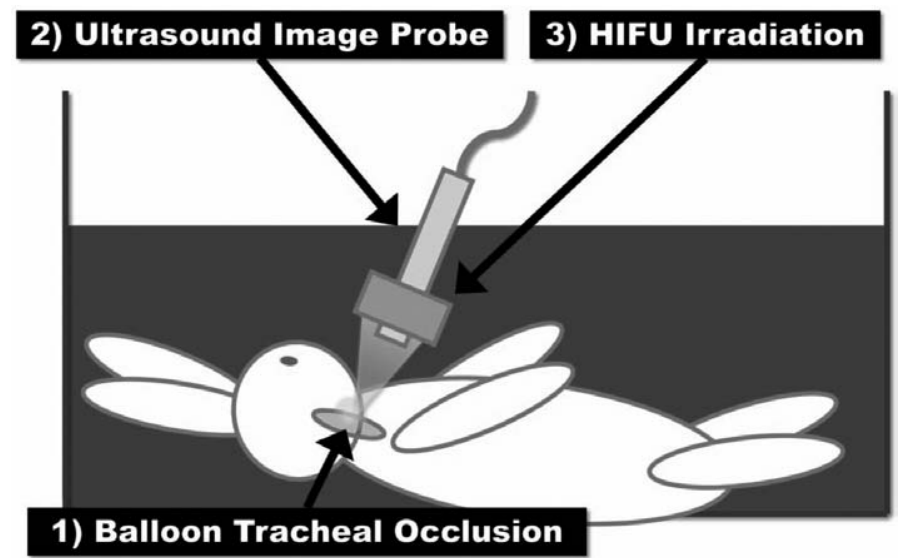

Fig. 1. A fetoscope was inserted in the trachea of each rabbit, through which a balloon was inflated and placed under ultrasound guidance. HIFU was then applied focusing on the back wall of the balloon under ultrasound guidance.

with heating waves) except that the HIFU exposure time was set for $15 \mathrm{~s}$ with an interruption of $200 \mathrm{~ms}$ between HIFU exposure cycles. This cycle was repeated up to five times as needed.

To objectively assess the HIFU-induced effects on the inflated intratracheal balloon and on the surrounding animal tissue in both experiments, the total dose of HIFU energy output [kJ] was determined by multiplying $\mathrm{I}_{\mathrm{SATA}}\left[\mathrm{W} / \mathrm{cm}^{2}\right]$, HIFU irradiated area $\left[\mathrm{cm}^{2}\right]$, and HIFU exposure time [s] together (I $\mathrm{I}_{\mathrm{SATA}}$ : HIFU intensity of spatial average and temporal average, HIFU irradiated area : means the cross-sectional area at the HIFU focal point). These energy values were evaluated statistically using a t-test and the outcome was expressed as means +/- S.D.

In addition, specimens of the trachea and surrounding tissues obtained from both experiments were stained with hematoxylin-eosin $(\mathrm{HE})$ to histologically evaluate the physical and/or mechanical effects of HIFU exposure.

These experiments were approved by the Animal Research Committee of the National Center for Child Health and Development (Approval No. A2006-007-C07) according to the Institutional Animal Care and Use Committee guidelines.

\section{Results}

\section{Experiment 1}

In all five rabbits, the balloon was destroyed by bursting almost instantaneously (Table 1). In four rabbits in which the balloon was placed between the vocal cord and the manubrium, balloon destruction was confirmed in the course of the first cycle of HIFU irradiation, whereas balloon destruction was recognized in the third cycle of HIFU exposure in a single case in which the balloon was accidentally placed just under the manubrium and carina.

The histological examination of the tracheal tissue demonstrated no clear thermal injury or denaturation at the site of HIFU irradiation. Although mechanical injury of the tracheal membranous wall was identified in four of the five animals (Fig. 2A), there was no evidence 
of likely thermal denaturation or coagulation as a direct effect of HIFU exposure (Fig. 2B). Indeed, the mechanical injury was observed fetoscopically in the course of initial balloon inflation in the trachea. Meanwhile, in two of the five animals, histological HIFU injuries were observed on the skin surface overlying the HIFU-exposed balloon (Fig. 3A, B).

\section{Experiment 2}

In one of the six cases, the balloons burst like those destroyed in experiment 1, while the remaining five balloons showed progressive deflation with an ultimate shrinkage within 12-24 hours at room temperature (Table 2). The deflation of five balloons was probably due to a

Table 1. Results of Experiment 1

\begin{tabular}{clllllll}
\hline Animal & Balloon location & $\begin{array}{l}\text { Injection } \\
\text { volume } \\
(\mathrm{ml})\end{array}$ & $\begin{array}{l}\text { Number } \\
\text { of HIFU } \\
\text { irradiation } \\
\text { cycles }\end{array}$ & $\begin{array}{l}\text { Energy } \\
\text { output for } \\
\text { total HIFU } \\
\text { dose }(\mathrm{kJ})\end{array}$ & $\begin{array}{c}\text { Skin } \\
\text { injury }\end{array}$ & $\begin{array}{c}\text { Tracheal } \\
\text { injury }\end{array}$ & Result \\
\hline 1 & $\begin{array}{l}\text { Between vocal } \\
\text { cord and } \\
\text { manubrium }\end{array}$ & 1.0 & 1 & 2.83 & $(-)$ & $(+)$ & Destruction \\
\hline $\begin{array}{l}\text { Between } \\
\text { manubrium and } \\
\text { carina }\end{array}$ & 1.0 & 3 & 8.49 & $(-)$ & $(-)$ & Destruction \\
\hline $\begin{array}{l}\text { Between vocal } \\
\text { cord and } \\
\text { manubrium }\end{array}$ & 1.0 & 1 & 2.83 & $(-)$ & $(+)$ & Destruction \\
$\begin{array}{l}\text { Between vocal } \\
\text { cord and } \\
\text { manubrium }\end{array}$ & 1.0 & 1 & 2.83 & $(+)$ & $(+)$ & Destruction \\
\hline $\begin{array}{l}\text { Between vocal } \\
\text { cord and } \\
\text { manubrium }\end{array}$ & 1.0 & 1 & 2.83 & $(+)$ & $(+)$ & Destruction \\
\hline
\end{tabular}
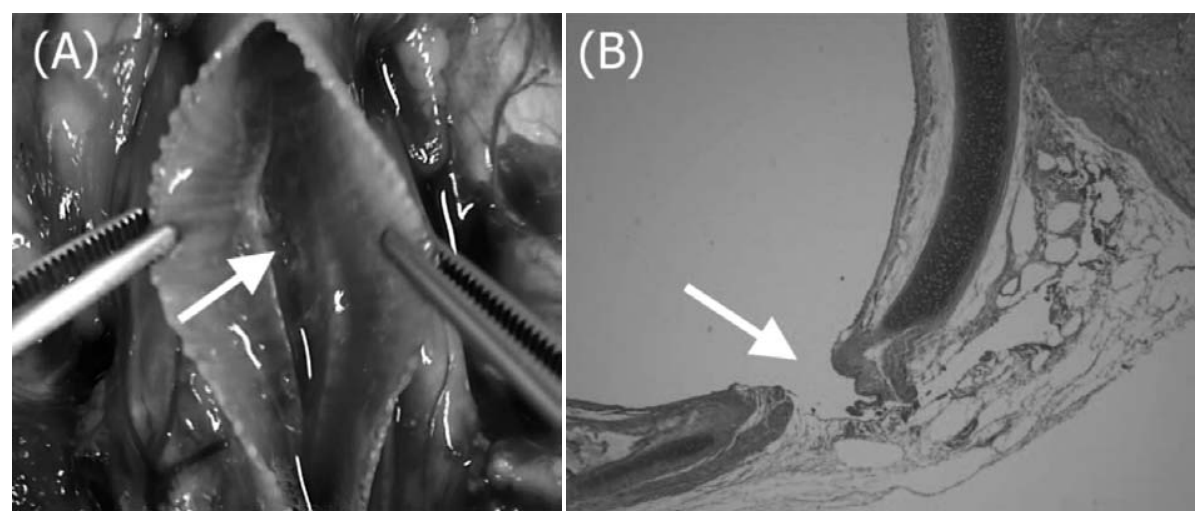

Fig. 2. Injury of the tracheal membranous wall (arrows) represented by macrophotography (A) and HE-staining (B) of a histological tissue section. The HEstained specimen showed no evidence of suspected thermal denaturation or thermal coagulation around the injury of the tracheal membranous wall. 
gradual slow leak of the injected fluid through the balloon wall through a minute fissure that was detected subsequently following a forceful injection of saline.

Two of the six cases showed mechanical injury of the tracheal membranous wall as observed in experiment 1 . Two of the six animals also showed injury to the skin lying over the HIFU-

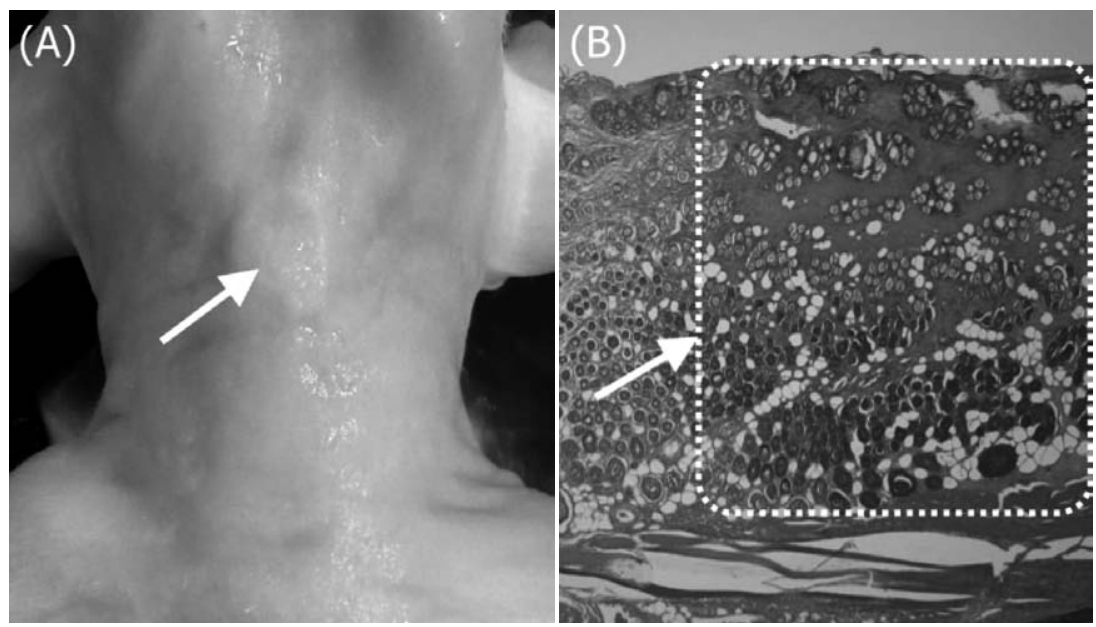

Fig. 3. Heat injuries (arrows) were observed on the skin surface of the anterior aspect of the trachea. (A) Macrophotography of the skin surface. (B) HE-stained section of trachea (area surrounded by dotted lines indicates the injury).

Table 2. Results of Experiment 2

\begin{tabular}{|c|c|c|c|c|c|c|c|}
\hline Animal & Balloon location & $\begin{array}{l}\text { Injection } \\
\text { volume } \\
(\mathrm{ml})\end{array}$ & $\begin{array}{l}\text { Number } \\
\text { of HIFU } \\
\text { irradiation } \\
\text { cycles }\end{array}$ & $\begin{array}{l}\text { Energy } \\
\text { output for } \\
\text { total HIFU } \\
\text { dose }(\mathrm{kJ})\end{array}$ & $\begin{array}{l}\text { Skin } \\
\text { injury }\end{array}$ & $\begin{array}{l}\text { Tracheal } \\
\text { injury }\end{array}$ & Result \\
\hline 1 & $\begin{array}{l}\text { Between vocal } \\
\text { cord and } \\
\text { manubrium }\end{array}$ & 0.6 & 3 & 2.41 & $(-)$ & $(+)$ & Destruction \\
\hline 2 & $\begin{array}{l}\text { Between } \\
\text { manubrium and } \\
\text { carina }\end{array}$ & 0.6 & 3 & 2.83 & $(-)$ & $(+)$ & Deflated \\
\hline 3 & $\begin{array}{l}\text { Between vocal } \\
\text { cord and } \\
\text { manubrium }\end{array}$ & 0.55 & 2 & 1.89 & $(+)$ & $(-)$ & Deflated \\
\hline 4 & $\begin{array}{l}\text { Between vocal } \\
\text { cord and } \\
\text { manubrium }\end{array}$ & 0.5 & 5 & 4.71 & $(-)$ & $(-)$ & Deflated \\
\hline 5 & $\begin{array}{l}\text { Between vocal } \\
\text { cord and } \\
\text { manubrium }\end{array}$ & 0.5 & 4 & 3.77 & $(-)$ & $(-)$ & Deflated \\
\hline 6 & $\begin{array}{l}\text { Between vocal } \\
\text { cord and } \\
\text { manubrium }\end{array}$ & 0.5 & 1 & 0.94 & $(+)$ & $(-)$ & Deflated \\
\hline
\end{tabular}




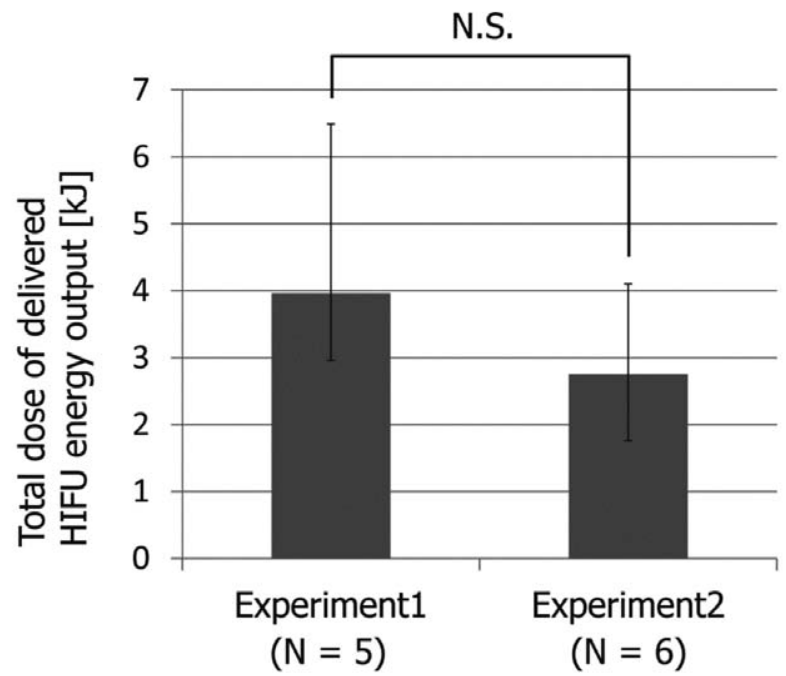

Fig. 4. Average and standard deviation of total doses of delivered HIFU in terms of energy output for Experiment $1 \quad(\mathrm{~N}=5)$ and Experiment $2(\mathrm{~N}=6)$. There was no significant difference between the results from experimental groups 1 and 2 , unpaired t-test $(t(9)=1.01, P=0.34)$.

targeted trachea.

Tables 1 and 2 also detail the "total dose of HIFU energy output" in experiments 1 and 2, respectively. As shown in Fig. 4, no significant difference in the delivered HIFU energy was found on average between the two experiments.

\section{Discussion}

In this study, we demonstrated that the trachea with a balloon occlusion can be re-opened instantaneously by HIFU irradiation alone. This experimental outcome suggests a strong likelihood that a fetus undergoing FETO to treat severe lung hypoplasia would not have to withstand a second prenatal fetoscopy to remove the balloon. HIFU has already been clinically used to ablate diverse tumors including prostate and breast cancers ${ }^{11,12)}$ as well as an acardiac twin to save the pump twin in cases of twin reversed arterial perfusion sequence ${ }^{13)}$.

Using an ultra-slow video camera and a transparent silicone tube as a substitute for an animal trachea, we could model a detailed process of HIFU destruction of the balloon ${ }^{14)}$. Interestingly, destruction or deflation of the intratracheal balloon using HIFU by our procedure did not seem to depend on its thermal effect alone, unlike in cases of tumor or tissue ablation. In our animal models, the HIFU irradiation first caused the fluid injected into the balloon to evaporate and form collections of minute gaseous bubbles, which rapidly expanded to a dense cluster located immediately beneath the front of the balloon. These bubbles are presumed to ultrasonically injure the front of the balloon owing to their large acoustic impedance, which provides the HIFU with high reflectivity (unpublished data). Worthy of note, we found no evidence of increased pressure on the silicone tube from inside the balloon immediately before bursting. 
In our experiment, the fluid for balloon injection was a mixture of perfluorocarbon (Nanodroplet) and clinically available ultrasound contrast medium (Sonazoid ${ }^{\mathbb{R}}$ ), both of which are proven to be clinically safe for human subjects. Perfluorocarbon is quite evaporative and biologically inactive, and can dissolve a large quantity of oxygen, leading to its clinical adoption for "liquid ventilation" in which fully oxygenated perfluorocarbon is injected into the trachea of human patients with severe respiratory dysfunction. In our case, we tested a substance produced from perfluorocarbon (i.e., Nanodroplet) to achieve HIFU destruction of the balloon because it was stable but readily gasified using HIFU, generating innumerable minute bubbles at a low temperature.

Along with our successful release of experimental tracheal occlusion, we encountered two categories of collateral damage in the entire course of the HIFU procedure. This damage comprised skin and subcutaneous tissue injuries and lacerations of the membranous back wall of the trachea.

First, the injuries to the skin and its underlying tissue in the direct path of the HIFU beam were assumed to be from mechanical and thermal causes. Mechanical injuries have been associated previously with the generation of "standing waves" overlying the border between the outside degassed water and the epidermal tissue. These waves, which are formed by reflected acoustic waves and endowed with doubly high acoustic pressure, are likely to cause intradermal cavitation with associated production of destructive shock waves ${ }^{15)}$. In addition, it has been suggested that vibratory energy converted from HIFU energy within the dermal tissue enables heat production, which subsequently provokes thermal injury. The mechanism underlying other skin injuries probably involves diverse multiple causes including a pre-planned sequence of HIFU exposure and the intratracheal location of the balloon, which potentially affects the angle of HIFU beam incidence and HIFU energy availability. Indeed, we found a tendency for reduced skin injuries when HIFU irradiation was carried out with a short-time interruption between HIFU exposure cycles (experiment 2). Meanwhile, we could not find any distinct correlations between the skin injuries and total dose of delivered HIFU energy.

Another major issue was a gross injury of the tracheal membranous back wall. This apparently mechanical injury was not caused by a rapid rise in the balloon pressure associated with its burst, but instead by balloon over-distension with an excessive injection volume (experiment 1). Experiment 2 subsequently revealed that we could achieve substantial reduction in the incidence of such injury by inflating the balloon with a smaller amount of fluid.

It should be noted that the outcome of our microscopic studies in the two described experiments was quite limited in terms of biological significance because we obtained the tissue specimens from experimental animals that were dead before the start of the procedure. Accordingly, we should use live animals in future to accurately investigate the histopathological damage caused by the HIFU procedure.

In conclusion, our feasibility study demonstrated that the FETO procedure could possibly be completed using HIFU alone, thus totally avoiding the currently required second fetoscopy. It is also expected that this development will enhance the safety and clinical uptake of the FETO procedure, leading to improved therapeutic outcomes for fetal lung hypoplasia associated with $\mathrm{CDH}$. We plan to further develop this promising HIFU technique. 


\section{Acknowledgements}

A part of this work was supported by Health and Labour Sciences Research Grants (H22-MIS-Norm-001) and JSPS Grants-in-Aid for Scientific Research (26282150).

\section{Conflict of interest disclosure}

The authors report no conflict of interest.

\section{References}

1) Haroon J, Chamberlain RS. An evidence-based review of the current treatment of congenital diaphragmatic hernia. Clin Pediatr (Phila). 2013;52:115-124.

2) Ali K, Grigoratos D, Cornelius V, et al. Outcome of $\mathrm{CDH}$ infants following fetoscopic tracheal occlusion-influence of premature delivery. J Pediatr Surg. 2013;48:1831-1836.

3) Deprest JA, Nicolaides K, Gratacos E. Fetal surgery for congenital diaphragmatic hernia is back from never gone. Fetal Diagn Ther. 2011;29:6-17.

4) Ruano R, Yoshisaki CT, Da Silva MM, et al. A randomized controlled trial of fetal endoscopic tracheal occlusion versus postnatal management of severe isolated congenital diaphragmatic hernia. Ultrasound Obstet Gynecol. 2012;39:20-27.

5) Cruz-Martinez R, Castanon M, Moreno-Alvarez O, et al. Usefulness of lung-to-head ratio and intrapulmonary arterial Doppler in predicting neonatal morbidity in fetuses with congenital diaphragmatic hernia treated with fetoscopic tracheal occlusion. Ultrasound Obstet Gynecol. 2013;41:59-65.

6) Kawabata K, Asami R, Azuma T, et al. Novel highly-selective and imaging-based ultrasound cancer treatment with phase-change nano-droplet. Drug Delivery Syst. 2010;25:456-465.

7) Kawabata K, Asami R, Azuma T, et al. Acoustic Response of Microbubbles Derived from Phase-Change Nanodroplet. Jpn J Appl Phys. 2010;49:07HF18.

8) Inoue T, Kudo M, Hatanaka K, et al. Usefulness of contrast-enhanced ultrasonography to evaluate the posttreatment responses of radiofrequency ablation for hepatocellular carcinoma: comparison with dynamic CT. Oncology. 2013;84 Suppl 1:51-57.

9) Omoto K, Matsunaga H, Take N, et al. Sentinel node detection method using contrast-enhanced ultrasonography with sonazoid in breast cancer: preliminary clinical study. Ultrasound Med Biol. 2009;35:1249-1256.

10) Shimizu J, Endoh R, Fukuda T, et al. Safety evaluation of superheated perfluorocarbon nanodroplets for novel phase change type neurological therapeutic agents. Perspect Med. 2012;1:25-29.

11) Thuroff S, Chaussy C. Evolution and Outcomes of $3 \mathrm{MHz}$ high intensity focused ultrasound therapy for localized prostate cancer during 15 Years. J Urol. 2013;190:702-710.

12) Stewart EA, Rabinovici J, Tempany CM, et al. Clinical outcomes of focused ultrasound surgery for the treatment of uterine fibroids. Fertil Steril. 2006;85:22-29.

13) Okai T, Ichizuka K, Hasegawa J, et al. First successful case of non-invasive in-utero treatment of twin reversed arterial perfusion sequence by high-intensity focused ultrasound. Ultrasound Obstet Gynecol. 2013;42:112-114.

14) Osawa S, Sato T, Yamashita H, et al. High-intensity focused ultrasound for fetal surgery: technique for removal of balloon occlusion. J Showa Univ Soc. 2016;76:193-198. (in Japanese).

15) Li JJ, Gu MF, Luo GY, et al. Complications of high intensity focused ultrasound for patients with hepatocellular carcinoma. Technol Cancer Res Treat. 2009;8:217-224.

[The publication of this paper was given a priority date] 